\title{
Hull prospective analysis of Botulinum Toxin type A (Botox) use in the treatment of chronic migraine
}

\author{
F Ahmed*, M Khalil, V Quarshie \\ From The European Headache and Migraine Trust International Congress \\ London, UK. 20-23 September 2012
}

\section{Introduction}

Botulinum toxin type A (BOTOX) is licensed for the prophylaxis of headaches in adults with chronic migraine $(\mathrm{CM})$. A prospective study was performed to examine the change in frequency of CM symptoms before and after treatment with BOTOX in the real-life setting.

\section{Methods}

Adults with CM were offered BOTOX after discussion of treatment options. Patients were injected intramuscularly as per PREEMPT, and maintained a headache diary for 30 days before/after BOTOX treatment. Data were collected for the number of headache, migraine and crystal clear (headache free) days. A responder was defined as $50 \%$ reduction in headache or migraine days, or an increment in crystal clear days twice that of the baseline in a 30-day period.

\section{Results}

Full data were available on 67 patients (16 males (mean age 47.2 years; range $26-76$ years); 51 females (mean age 42.4 years, range 19-70 years) who received BOTOX. 57/ 67 (85\%) tried 3 preventive treatments and 36/67 (53.7\%) were overusing analgesics. The median number of headache days reduced from 27 before BOTOX to 18 after $\operatorname{BOTOX}(\mathrm{p}<0.001)$; the median number of migraine days reduced from 12 before to 7 after $(\mathrm{p}<0.001)$; the median number of crystal clear days increased from 3 before to 12 after $(\mathrm{p}<0.001)$. Of the cohort, $34 \%$ reported $50 \%$ reduction in headache days, $48 \%$ a $50 \%$ reduction in migraine days and $54 \%$ a $50 \%$ reduction in crystal clear days. Triptan days reduced from 8 before BOTOX to 3 after $(p<0.001)$. Data on days off work was available for
$17 / 67$ patients; in these, the median number of days off work per month reduced from 6 before to 3 after BOTOX (0.004). 13/67(19.4\%) reported adverse events; 8 with pain at injection sites, 1 with worsening headache, 3 could not frown and 1 fainted during $\mathrm{Rx}$.

\section{Conclusions}

BOTOX is a valuable addition to preventive treatment options in patients with CM. It significantly reduces the number of headache and migraine days, and significantly increases the number of crystal clear days in a real-life setting.

\section{Conflict of interests}

FA received honorarium as advisory board member from Allergan.

Published: 21 February 2013

Reference

1. Blumenfeld A, Silberstein SD, Dodick DW, Aurora SK, Turkel CC, Binder WJ: Method of injection of onabotulinumtoxinA for chronic migraine: a safe, well-tolerated and effective treatment paradigm based on the PREEMPT clinical program. Headache 2010, 50(9):1406-18.

doi:10.1186/1129-2377-14-S1-P187

Cite this article as: Ahmed et al.: Hull prospective analysis of Botulinum Toxin type A (Botox) use in the treatment of chronic migraine. The Journal of Headache and Pain 2013 14(Suppl 1):P187. 